\title{
Young children's recognition as a function of the spacing of repetitions and the type of study and test stimuli
}

\author{
ALLYSON CAHILL and THOMAS C. TOPPINO \\ Villanova University, Villanova, Pennsylvania
}

\begin{abstract}
Preschool and second-grade children studied a list of either pictures or their corresponding labels (words) and, $48 \mathrm{~h}$ later, received a yes/no recognition test involving either the same or the opposite type of stimuli. Some items on the study list were presented twice, with repetitions either massed or distributed (spaced). The results indicated that, when both study and test stimuli were pictures, the children's recognition was better than when study and/or test stimuli were words. The children also recognized distributed repetitions better than massed repetitions (a spacing effect). However, the spacing effect was not altered by the type of stimuli presented for study and/or test. The results suggest that the spacing effect is mediated by a semantic representation and that, under these circumstances, it is produced by relatively automatic processes.
\end{abstract}

The effect of repetition is often severely limited when an item of information is given massed presentations (MP), in which its occurrences are presented in immediate succession. The effect of repetition is usually greater when the item of information is given distributed presentations (DP), in which its occurrences are separated by the passage of time and/or other events. The fact that DP items are remembered better than MP items is known as the spacing effect, which has been observed in a wide variety of memory tasks (e.g., recall, recognition, and frequency judgments) involving a wide range of task parameters including different types of stimulus items, various presentation rates, and both visual and auditory modalities of presentation.

Most theoretical accounts of the spacing effect attribute the phenomenon either to inadequate processing of one occurrence of an MP item (deficient-processing theories) or to a retrieval advantage conferred on DP items because they presumably are encoded differently on each presentation (encoding-variability theories). (See Hintzman, 1974, for a somewhat dated but still useful review.) An orthogonal theoretical issue concerns the degree to which the underlying mechanism involves voluntary, strategic processes, or relatively involuntary, automatic processes.

Attempts to determine whether a deficient-processing or an encoding-variability mechanism produces the spacing effect have proved to be inconclusive. Both kinds of theory are consistent with much of the available evidence, but not with all of it. For example, deficient-processing theories have difficulty explaining nonmonotonic effects

This research was supported by National Institute of Child Health and Human Development Grant HD21209 awarded to the second author. Correspondence should be addressed to T. C. Toppino, Department of Psychology, Villanova University, Villanova, PA 19085. of increased spacing, such as those obtained by Glenberg $(1976,1977)$. On the other hand, studies frequently have failed to support the fundamental assumption underlying encoding-variability theories-that varied encoding increases the probability of successful retrieval (e.g., Maki \& Hasher, 1975; Postman \& Knecht, 1983).

Attempts to assess whether the spacing effect is produced by automatic processes or by voluntary, strategic processes have met with somewhat greater success. With respect to free recall, the available data consistently favor an automatic-process explanation. For example, numerous studies have found that college students exhibit a comparable spacing effect in both intentional- and incidentallearning conditions (e.g., Jensen \& Freund, 1981; Shaughnessy, 1976). Converging evidence has been provided by developmental studies. Preschool children, who are thought not to use effective mnemonic strategies (e.g., BakerWard, Ornstein, \& Holden, 1984; Myers \& Perlmutter, 1978), exhibit a spacing effect in free recall (Rea \& Modigliani, 1987; Toppino, 1991, 1993). Furthermore, there is no evidence that the magnitude of the spacing effect changes as a function of increasing age (Rea \& Modigliani, 1987; Toppino, 1991).

In the case of recognition, the data concerning the issue of voluntary versus automatic processing are less consistent. Greene $(1989,1990)$ has reported that college students exhibit a spacing effect in recognition under intentionallearning conditions but not under incidental-learning conditions. He interpreted these findings as indicating that the spacing effect in recognition is the result of voluntary, strategic processes. However, Toppino, Kasserman, and Mracek (1991) recently found that preschool children exhibited a spacing effect in recognition and that the effect remained unchanged with increasing age. These findings are more consistent with an automatic-process explanation of the spacing effect in recognition. 
The present research was designed to further explore the spacing effect in the recognition performance of young children. Toppino et al. (1991) used colored pictures as stimuli in their developmental study of the spacing effect in recognition, whereas most researchers, including Greene, have investigated the recognition of word stimuli. It seemed possible that picture stimuli, with their rich, distinctive, visual cues, might be particularly likely to support recognition on the basis of familiarity judgments, which are usually assumed to reflect data-driven processes closely related to the perceptual characteristics of the stimuli (e.g., Jacoby \& Dallas, 1981; Mandler, 1980). Some authors have also suggested that the kind of information that supports familiarity judgments is encoded in a more obligatory, automatic fashion than other, more elaborative, forms of information (e.g., Humphreys \& Bain, 1983). Thus, if picture recognition is based on familiarity judgments, it seems possible that not only recognition, but also the spacing effect, might reflect the operation of relatively automatic processes.

In the present experiment, we independently varied the nature of the stimuli presented for study (pictures vs. their auditorily presented labels) and the nature of the test stimuli (pictures vs. their auditorily presented labels). We expected to replicate Toppino et al. (1991) by obtaining a spacing effect in young children when picture stimuli were used for both study and test. We sought to determine whether the spacing effect in recognition would generalize to the use of verbal stimuli for both study and test. And, finally, if the spacing effect in young children is limited to the use of a familiarity-based recognition process, we expected the spacing effect to be eliminated when the nature of the stimuli changed from study to test (e.g., study pictures/test words and study words/test pictures).

\section{METHOD}

\section{Design}

The experiment was designed as a 2 (grade level, preschool vs. second grade) $\times 4$ (study-test condition, pictures-pictures vs. pictureswords vs. words-pictures vs. words-words) $\times 3$ (repetition/spacing condition, 1P [once-presented] vs. MP vs. DP) mixed factorial with the last factor manipulated within subjects.

\section{Subjects}

Ninety-six preschoolers $(M=53.2$ months of age; range $=42-59$ months) and 96 second graders $(M=98.2$ months; range $=90-105$ months) served as subjects. Twelve males and 12 females from each age level were randomly assigned in blocks of 4 to each of the four study-test conditions.

\footnotetext{
Materials

Two list structures were devised, each containing 66 presentation positions. The first and last 7 positions were reserved for once-presented items, which served as primacy and recency buffers, respectively. The middle 52 positions were reserved for 12 IP filler items, 8 critical 1P items, $8 \mathrm{MP}$ items, and $8 \mathrm{DP}$ items, whose occurrences were separated by a lag of 4 presentation positions. Positions for the fillers, 1P, MP, and DP items were distributed evenly through the list so that half of each type of item occurred in each half of the list. Also, the mean serial positions of the second occurrences of MP and DP items were equated with one another and with the mean serial position of critical $1 \mathrm{P}$ items.
}

Fifty pictures (photographs) of common objects or their corresponding labels were used to create six study lists, three involving each list structure. After assigning items to conditions and slots in a given list structure, a Latin-square principle was used to generate two more lists with each structure so that the same set of items would be used equally often in the IP, MP, and DP conditions.

Six recognition test lists were constructed, three for use following study lists associated with each list structure. The test lists consisted of 24 targets from the study list (i.e., 8 IP, 8 MP, and 8 DP) mixed in a sequence that also included 24 new items (foils). Targets and foils were randomly assigned to serial positions by using a Gellerman (1933) series.

\section{Procedures}

The experimenter met individually with each subject for two sessions at the child's school. The experimenter introduced the session by pointing out two stacks of pictures, which consisted of the study list and the test list. The child was told that the experimenter would show or tell about each picture in the "big pile" (study list). Later, the child would be asked to identify the items in the "smaller pile" (test list) as being the same as, or different from, the items in the study list. When the study list was presented as pictures, the experimenter manually presented the photographs in the large stack to the child. When the study list was presented as words, the experimenter again turned over one picture at a time but, instead of showing the picture to the child, the experimenter pronounced the name (label) of the pictured object. In either case, one item was presented every $2 \mathrm{sec}$. The children were not required or encouraged to label the pictures or repeat the labels as they were presented.

The second session took place after a 48-h retention interval. The children were reminded of the pictures seen or described by labels in the previous session. A yes/no recognition test was then administered. Test items were presented successively and the children indicated whether or not each item had occurred in the previous study session. In presenting the test items, the experimenter turned over one photograph at a time and either showed it to the child (picture test condition) or pronounced its label without showing the child the picture (word test condition). In either case, the children proceeded through the test list at their own pace. They were given no feedback about the correctness of their responses.

\section{RESULTS}

The repetition/spacing factor can be viewed as two logically separable variables: Repetition (once-presented vs. twice-presented items collapsed across spacing condition), and the spacing between repetitions (MP vs. DP). The effects of these two variables were examined in separate $2 \times 4 \times 2$ (grade level $\times$ study-test condition $\times$ repetition or spacing) analyses of variance with repeated measures on the last factor. These analyses were conducted on both hit rate (HR) and $d^{\prime}$ data. Although the results for the two dependent measures were generally consistent, the effects of between-subject variables on hit rate were difficult to interpret due to differences in false-alarm rates. Therefore, only the analyses of the $d^{\prime}$ data are reported, although the corresponding mean HRs will be noted.

The analysis of repetition indicated that twice-presented (2P) items were recognized better than $1 \mathrm{P}$ items $[F(1,184)$ $\left.=79.54, M S_{\mathrm{e}}=.34, p<.001\right]$. For $1 \mathrm{P}$ and $2 \mathrm{P}$ items, respectively, the mean $d^{\prime}$ was 1.28 and 1.81 (mean HR $=.57$ and .72$)$. Both grade level $[F(1,184)=11.91]$ and study-test condition $[F(3,184)=49.29]$ yielded significant main effects $\left(M S_{\mathrm{e}}=.81, p<.001\right)$, but the nature 
of these effects will be described in the context of the next analysis, in which they also occurred. There were no significant interactions (all $F \mathrm{~s} \leq 2.69, p>.10$ ).

The analysis of spacing indicated that there was a significant spacing effect with DP items (mean $d^{\prime}=1.90$; mean $\mathrm{HR}=.74$ ) being recognized better than MP items [mean $d^{\prime}=1.73$; mean HR $=.69 ; F(1,184)=6.32$, $\left.M S_{\mathrm{e}}=.42, p<.02\right]$. There was a significant main effect of study-test condition $\left[F(3,184)=45.32, M S_{\mathrm{e}}=\right.$ $1.08, p<.001$ ], with Tukey's paired comparisons indicating that the picture-picture condition (mean $d^{\prime}=$ 2.87 ; mean $\mathrm{HR}=.88$ ) yielded better recognition performance than the other three conditions, which did not differ significantly from one another (mean $d^{\prime} \mathrm{s}=1.59,1.32$, 1.47 , and mean HRs $=.67, .65, .67$, for the pictureword, word-picture, and word-word conditions, respectively). Finally, there was a significant main effect of grade level $\left[F(1,184)=4.29, M S_{\mathrm{e}}=1.08, p<.05\right]$, indicating that the preschoolers (mean $d^{\prime}=1.92$; mean $\mathrm{HR}=.71)$ performed better than the second graders (mean $d^{\prime}=1.70$; mean HR $=.72$ ). No interactions approached significance $(F \mathrm{~S}<1.00)$.

\section{DISCUSSION}

When both study and test stimuli were pictures, the children's overall recognition performance was better than when words were used as study stimuli, test stimuli, or both. This picture-superiority effect, especially in the absence of systematic overt labeling, is consistent with the assumption that children's recognition performance benefits from the relative distinctiveness of the visual representations of pictures (e.g., Nelson, 1979). However, this phenomenon appears to be independent of the spacing effect. Both the preschoolers and second graders exhibited a spacing effect, and the size of the effect was uninfluenced by the pictorial or verbal-auditory nature of the stimuli.

The fact that the young children exhibited a spacing effect when both study and test stimuli were pictures replicated the findings of Toppino et al. (1991). It is particularly interesting that the spacing effect in the present experiment was undiminished in the two conditions in which the nature of the stimuli changed from study to test. This suggests that the spacing effects obtained in the present experiment as well as in the previous work by Toppino et al. were not limited to conditions in which recognition is mediated by familiarity judgments based on the perceptual characteristics of the stimuli. Apparently, the spacing of repetitions exerts its influence by affecting the encoding of relatively abstract (and probably semantic) information that can be accessed by either pictorial or verbal/acoustic cues. A similar conclusion was reached by Hintzman, Block, and Summers (1973), who found that the spacing effect in a frequency-judgment task was unaffected by whether successive presentations of items that were repeated in the study list occurred in the same or different modalities.

The results of the present study are difficult to reconcile with Greene's (1989) theory of the spacing effect in recognition. Greene proposed that, as each item is presented, subjects allocate rehearsal to the item in inverse proportion to how well learned they think it is. When the second presentation of an MP item occurs, subjects experience it as very familiar; they mistakenly believe that it is already well learned, and give it little extra rehearsal. In contrast, the second occurrence of a DP item seems less familiar, due to the spacing between its presentations and, thus, receives more rehearsal. The result is that DP items are recognized better than MP items because the former receive more rehearsal than the latter. Young children, however, do not spontaneously employ the kind of sophisticated rehearsal processes hypothesized by Greene.

Interpretation of the present findings in relation to Greene's theory is complicated, and perhaps weakened somewhat, by the fact that the preschoolers unexpectedly performed better than the second graders.
However, we see no compelling reason to alter the essential conclusion. We cannot determine the extent to which the performance reversal was due to exceptional performance by the preschoolers, poor performance by the second graders, or some combination of both. However, there is no reason to believe that our second graders were advanced for their age. And, although children of this age may have begun to engage in some simple forms of rehearsal, they do not seem to modify their rehearsal activity on the basis of how well learned or how difficult they judge information to be (e.g., Bisanz, Vesonder, \& Voss, 1978; Dufresne \& Kobasigawa, 1989; Masur, McIntyre, \& Flavell, 1973). It seems more likely that relatively automatic processes underlie the spacing effect in recognition.

This conclusion is also supported by the experiments of Toppino et al. (1991), in which no unusual age effects were encountered. They obtained a spacing effect in 4-year-old children and found no evidence of change in the spacing effect with increasing age between the ages of 4 and adulthood, in spite of the fact that enormous changes in the sophistication of rehearsal processes is known to take place during this period (e.g., Ornstein, Baker-Ward, \& Naus, 1988).

As we noted earlier, it seems most likely that a semantic representation mediated the spacing effect in recognition in both the present study and in the study by Toppino et al. (1991). This may be noteworthy in light of Challis's (1993) recent criticism of Greene's (1989) experiments. Challis argues that Greene confounded intentionality and level of processing such that intentional-learning conditions involved semantic processing, whereas incidental-learning conditions involved nonsemantic processing. Thus, instead of indicating that voluntary processes are necessary for the spacing effect to occur in recognition, Greene's findings may be seen as indicating that semantic processing is necessary. This suggests a possible reconciliation of Greene's findings (but not his theory) with the developmental invariance obtained by Toppino et al. Perhaps, the spacing effect in recognition is produced by relatively automatic processes, provided that stimulus information is processed at a semantic level of analysis. Future research might profitably explore the merits of this hypothesis.

\section{REFERENCES}

Baker-Ward, L., Ornstein, P. A., \& Holden, D. J. (1984). The expression of memorization in early childhood. Journal of Experimental Child Psychology, 37, 555-575.

Bisanz, D. L., Vesonder, G. T., \& Voss, J. F. (1978). Knowledge of one's own responding and the relation of such knowledge to learning. Journal of Experimental Child Psychology, 25, 116-128.

Challis, B. H. (1993). Spacing effects on cued-memory tests depend on level of processing. Journal of Experimental Psychology: Learning, Memory, \& Cognition, 19, 389-396.

Dufresne, A., \& Kobasigawa, A. (1989). Children's spontaneous allocation of study time: Differential and sufficient aspects. Journal of Experimental Child Psychology, 47, 274-296.

Gellerman, L. W. (1933). Chance orders of alternating stimuli in visual discrimination experiments. Journal of Genetic Psychology, 42, 206-208.

GLENBERG, A. M. (1976). Monotonic and nonmonotonic lag effects in paired-associate and recognition memory paradigms. Journal of Verbal Learning \& Verbal Behavior, 15, 1-16.

GLENBERG, A. M. (1977). Influences of retrieval processes on the spacing effect of free recall. Journal of Experimental Psychology: Human Learning \& Memory, 3, 282-294.

GREENE, R. L. (1989). Spacing effects in memory: Evidence for a twoprocess account. Journal of Experimental Psychology: Learning, Memory, \& Cognition, 15, 371-377.

GreENE, R. L. (1990). Spacing effects on implicit memory tests. Journal of Experimental Psychology: Learning, Memory, \& Cognition, 16, 1004-1011.

Hintzman, D. L. (1974). Theoretical implications of the spacing effect. In R. L. Solso (Ed.), Theories in cognitive psychology: The Loyola Symposium (pp. 77-99). Hillsdale, NJ: Erlbaum.

Hintzman, D. L., Block, R. A., \& Summers, J. J. (1973). Modality tags and memory for repetitions: Locus of the spacing effect. Journal of Verbal Learning \& Verbal Behavior, 12, 229-238. 
Humphreys, M. S., \& Bain, J. D. (1983). Recognition memory: A cue and information analysis. Memory \& Cognition, 11, 583-600.

JACOBY, L. L., \& DALLAS, M. (1981). On the relationship between autobiographical memory and perceptual learning. Journal of Experimental Psychology: General, 110, 300-340.

Jensen, T. D., \& Freund, J. S. (1981). Persistence of the spacing effect in incidental free recall: The effect of external list comparisons and intertask correlations. Bulletin of the Psychonomic Society, 18, 183-186.

MAKI, R. H., \& HASher, L. (1975). Encoding variability: A role in immediate and long-term memory. American Journal of Psychology, 88, 217-231.

MandleR, G. (1980). Recognizing: The judgment of previous occurrence. Psychological Review, 87, 252-271.

Masur, E. F., McIntyre, C. W., \& Flavell, J. H. (1973). Developmental changes in apportionment of study time among items in a multitrial free recall task. Journal of Experimental Child Psychology, 15, 237-246.

Myers, N. A., \& Perlmutter, M. (1978). Memory in the years from two to five. In P. A. Ornstein (Ed.), Memory development in children (pp. 191-218). Hillsdale, NJ: Erlbaum.

Nelson, D. L. (1979). Remembering pictures and words: Appearance, significance, and name. In L. S. Cermak \& F. I. M. Craik (Eds.), Levels of processing in human memory (pp. 45-76). Hillsdale, NJ: Erlbaum.
Ornstein, P. A., Baker-Ward, L., \& Naus, M. J. (1988). The development of mnemonic skill. In F. E. Weinert \& M. Perlmutter (Eds.), Memory development: Universal changes and individual differences (pp. 31-50). Hillsdale, NJ: Erlbaum.

Postman, L., \& Knecht, K. (1983). Encoding variability and retention. Journal of Verbal Learning \& Verbal Behavior, 22, 133-152.

Rea, C. P., \& Modigliani, V. (1987). The spacing effect in 4- to 9year-old children. Memory \& Cognition, 15, 436-443.

Shaughnessy, J. J. (1976). Persistence of the spacing effect in free recall under varying incidental learning conditions. Memory \& Cognition, 4, 369-377.

TopPINO, T. C. (1991). The spacing effect in young children's free recall: Support for automatic-process explanations. Memory \& Cognition, 19, 159-167.

TopPINo, T. C. (1993). The spacing effect in preschool children's free recall of pictures and words. Bulletin of the Psychonomic Society, 31, 27-30.

Toppino, T. C., Kasserman, J. E., \& Mracek, W. A. (1991). The effect of spacing repetitions on the recognition memory of young children and adults. Journal of Experimental Child Psychology, 51, 123-138.

(Manuscript received June 7, 1993.) 